\title{
Language Production and Comprehension: The Effect of Pre-school Aged Siblings on Toddlers Language Development
}

\author{
Elham Malmeer \\ Department of English Teaching, Science and Research Branch, Islamic Azad University, Kermanshah, Iran \\ Nader Assadi \\ Islamic Azad University, Ahar Branch, Iran
}

\begin{abstract}
Despite previous works showing that mothers, fathers, and siblings provide input to their toddler, the role of siblings on specific changes that they may cause, remains obscure. Since most work in this area has concentrated on the input provided by parents, this study extended prior work by comparing how specifically parents and sibling could influence different aspects of language development in toddlers up to age 24 months. 20 children $(1 ; 8)$ were videotaped interacting with their family members. Two groups of children were compared in this study: group A) toddlers who do not have a sibling, group B) toddlers who have a preschoolaged sibling (4:8). To see if there were a significant difference between the toddler's comprehension and production abilities, two separate t-tests were compared. Analysis of groups revealed that group A was superior on production but group $B$ acted better in comprehension. These results are discussed in terms of quality and quantity of the input provided by family members.
\end{abstract}

Index Terms - language comprehension, language production, input, toddlers, first language

\section{INTRODUCTION}

The role of input in the child's language acquisition is undeniably crucial. But how the language and language potential of the child is developed by the family members around? This question has been investigated by many researchers. Due to the plenty of researches which has been done in this field, a large body of literature is provided on the characteristics of parental input, especially, phenomenon of CDS or 'motherese (McLaughlin, 1998; Rondal, 1981; Wells and Robinson, 1982). Recent studies have revealed that families provide a comparable amount of linguistic input to their children but the quality of this input is different among the families which lead to differences in child language potentials. Accordingly some children are categorized as delayed or advance talkers regarding their abilities in language. It also has been suggested that the speech addressed to children is carefully grammatical and lack the usual hesitation and false starts common in adults to adults' speech (Debra C Vigil, Jennifer Hodges and Thomas Klee, 2005). More research studies on parental input confirm earlier evidence, demonstrating the selectivity of parental linguistic input to their children. This selectivity could even be seen in communicative interactions between older and younger siblings, for example in one of few studies about the interaction between siblings and younger children, Dune and Kendrick (1982) found that there is a systematic adjustment in 2and 3 year old children speech to 14month infants, But the question is, whether the quality and the quantity of these adjustments, among different members of the family, including father, mother, and siblings, are the same or not.

Language means communication, and communication is an interactive process in a real setting, which include parents and the other children around. Most research on child's language acquisition is investigating adult-child dyads (primarily mother-child dyads) when in fact many children develop their language ability in a polyadic settings (Lieven, 1994). As Nelson, Bonvillian, Denninger, Kaplan \&Baker (1984) argued, 'through research that details and differentiates the actual pattern of input from multiple sources is very badly needed to give us a realistic picture of the child's language acquisition process'. In a study which was done by Oshima-Takane, Goodz \& Derevensky (1996) it was revealed that young children $(1 ; 10)$ who have siblings, spent between 60 and 74 hours per week in a setting which is triad, a caregiver, child and sibling. Language development involves multiple factors, both within the child and the child's social environment to learn language. A child must attend the input in his or her environment in a sociolinguistic context in order to pair words with objects or events. There are three main sources for this involvement, Mothers, fathers and the siblings around.

Sibling's Input VS Mother's Input

The quality and quantity of the input which is provided by sibling and young children around is quite different from that which is provided by parents, especially mothers. According to Bridge Hypothesis (Barton \& Tomasello 1994, Berko-Gleason 1975, Mannle\& Tomasello 1987), sibling(s) and father are not as flexible conversational partners as the mother is. It has also been stated that more challenging context for conversation and interaction is provided by siblings 
and the father due to their unfamiliarity with the child's current language skill's level. Barton \& Tomasello (1994) argued that these differences will influence the pragmatic-conversational aspects of communication, such as the child's interpretation of the language in a given context. Mothers also tend to talk to their children in quite a different manner. A phenomenon known as 'Motherese' or CDS is characterized by shorter, simpler, slower, clearer utterances which have fewer hesitation and false starts with a lot of repetition of phrases, words and the whole utterance. Mothers speech addressed to the child also tend to be higher in pitch with exaggerated intonation patterns and rising tones (Claire Elizabeth Andersen and Julie V. Marinac, 2007). On the other hand it has been found that siblings' speech contain a higher proportion of attentional utterances and repetitions than that of the mothers.

The differences in the input provided to the child from different members of the family could also be in the quantity of the input addressed to the toddler.Although, several studies demonstrated that mothers (Hirsh-Pasek, Treiman \& Schneiderman, 1984; Demetras, Post \& Snow, 1986; Farrar, 1992) fathers (Penner, 1987; Bohannon \& Stanowicz, 1988), and even siblings (Strapp, 1993) recast or repeat with corrections following children's grammatical errors, Siblings play a somewhat different role in providing the feedback. In a triad settings the pre-schooled siblings tend to provide less corrective feedback than adults (Tomasello \& Mannle 1985) and in the sibling - child interaction again siblings tend to provide less corrective feedback (Mannle, Barton Tomasello 1991, Strapp 1993, 1999). Barton and Tomasello (1991) found that in $83 \%$ of the time preschool-aged siblings failed to acknowledge the infant. This input is even affected on the presence of a sibling (Barton \& Tomasello 1991, Jones \& Adamson 1987, Post1995, Schaffer \& Liddell 1984, Tomasello \& Mannle 1985, Wellen1985, Woollett 1986). Parents tend to produced fewer recasts to the child on the presence of a sibling (Strapp1999, Wellen 1985). In another study by Wellen (1985), it has been revealed that mothers produced fewer recasts in the mother-sibling-infant triad than in the mother-infant dyad settings. But what the research is intended to find is the recast and input provided by the siblings as well. Unfortunately, neither study considered recasts produced by siblings.

Even toddler quality and quantity of interaction is different, regarding who he is interacting with in the family. Tomasello, Farrar \& Dines (1983) in their studies proposed that regarding the child conversational partner, the child expectations are different. Children are less likely to imitate their fathers and siblings recast as the child has to put more attention in to practice while interacting with them. In another study which was done by Strapp \& Federico (2000) it was revealed that, children appear to imitate most often in settings where the mother is present. Therefore toddlers' response to negative evidence and non corrective feedbacks vary considerably across family configurations. Although these studies tried to inspect the role of siblings in the process of child's language development but they didn't specify how specifically the input provided by sibling could affect the process of language development in toddlers.

\section{The Current Study}

As it was shown up to here, it's so hard to neglect the role which siblings could play in the development of the toddler's language. Certainly more evident on the role of interaction between the child and his or her sibling is needed. The specific purpose of the present study was to explore the Effect of Pre-School Aged Siblings on Toddlers Language Development. Will toddlers having a preschool aged sibling differ with the ones who don't have a young sibling at home? For this purpose the following research question was proposed: Is there any significant diffrences in language production and comprehension between the children who have pre-school aged sibilings at home and the children who don't.

Based on the above question the following null-hypothesis can be conceived:

$H$.there is no significant difference in language production and comprehension between the children who have preschool aged sibilings at home and the children who don't.

\section{METHOD}

\section{A. Participants}

20 mothers and their toddlers participated in this study. 10 boys and 10 girls( 5 of each had a pre- school aged sibling at home) were videotaped at their homes during a month (approximately twice a week). The children in this study are chosen from the age group of 18 and 24months of age (mean age 22.7) due to the researcher's intrest in the toddlers intentional behavior. As it has been revealed the children do not show intentional behavior untill they are about 9-10 months old (Bates, 1979). Intentional behaviors are seen for the first time mostly during the second half of the first year. All the children had been raised in a monolingual persian environment. All mothers were housewifes and all the children were from two- parent families. Families ranged from lower middle to upper middle class in socioeconomic status. The primary language spoken in all the participants' home was persian. The criteria were that the children: must not have had any previous speech therapy/pathology input; have no known medical or neurological deficits and have normal hearing.

\section{B. Procedure}

Families were chosen by the reasercher from child care centers and play ground centers with the consent from the director of the organization. On the basis of the personal interviewing with parents, the children were categorized into two groups, 10 in each. Group A) an only child about 18 to 24 monthes, and group B) a child about 18 to 24 monthes with a preschool- aged sibling(s). families were asked to play with their children at home for about fifteen minutes and 
videotape the procedure. The resercher sometimes participated in the videotaping. In group A. there were only parents who played with the child, and in group B. there also was a sibling who participated in the play.Every session the child and his family sat on the floor and play with the same instruments that they used to play. All the families were told to act as normally as possible as if there was no vidiotaping, in order not to affect the child's behavior.After transcibing all the speech samples, the researcher (followin guidline suggested by CSBS DP Infant-Toddler Checklist)categorized them into three general categories:A:Sounds B: words C: understanding .

A: Toddlers' sounds: Sound samples were marked and coded based on: 1) Child's uses of sounds or words to get attention or help, 2) The abilityof the child to string sounds together such as uh oh, mama, baba, bada, 3) The number of the consonont sounds that the child use $m a, n a, b a, d a, g a, w a, l a, y a, s a$, sha.

B: Toddlers' words: Word samples were marked and coded based on: 1) The number of the meaningful words that is recognizable in the childs speech, 2) the number of telegraphic or two- word utterances.

C: Toddlers' understanding: The samples were coded and marked based on: 1) The child's attention to the family member by looking or turning toward them when calling his/her name, 2) The number of the different words or phrases that the child understand without pointing to them.

All the transcriptions were coded based on these three groups: not yet, sometimes, often and they were marked.

\begin{tabular}{|l|l|}
\hline \hline \multicolumn{1}{|c|}{ Maximum possible scores } & \multicolumn{2}{|c|}{} \\
\hline Language production & $\mathbf{8}$ \\
\hline Sounds & $\mathbf{6}$ \\
\hline Words & $\mathbf{6}$ \\
\hline \hline Language Comprehension. \\
\hline Understanding \\
\hline \hline
\end{tabular}

\section{RESULTS}

This study was desigend to to investigate the possible effect of the pre- school aged siblings on toddlers language development.so the foloowing research question was proposed:

I s there any significant diffrences in language production and comprehension between the children who have preschool-aged sibilings at home and the children who don't.

Based on this question the following null hypothesis was proposed:

There there is no significant difference in language production and comprehension between the children who have pre-school aged sibilings at home and the children who don't.

utterances were coded from 20 families during a month. They were hand coded and marked by the researcher. The researcher scored sub parts related to hypothesisshe made earlier. she obtained two seprate scores for each participant.A) speech composite. B) their comprehension ability

Data were entered into SPSS 13.0 for windows for statistical analysis, where descriptive statistical procedures and further calculations were carried out. To see if there were significant difference between the reported amout of language development in group A children and group B, two independent samples t-tests were applied. To determine significance throughout the study, the significant level was set at $\mathrm{p}<.05$.

\section{Toddlers Scores On Production Ability}

The children ability to produce sounds and words score in two groups was entered into SPSS. As it is clear from the result there was a significant diffrence in the speech production and comprehension of children who had a pre-school aged sibling at home and thoese who didn't. The results of analysis summerizing the descriptive statistics related to the speech composite of the two groups is presented in table 1.

TABLE 1

DESCRIPTIVE STATISTICS: RESULTS OF PAIRED SAMPLE T-TEST RELATED TO PRODUCTION ABILITY.

\begin{tabular}{|c|c|c|c|c|c|c|c|}
\hline & & \multicolumn{5}{|c|}{ Paired Differences } & \multirow[b]{3}{*}{$\mathrm{t}$} \\
\hline & & \multirow[b]{2}{*}{ Mean } & \multirow{2}{*}{$\begin{array}{l}\text { Std. } \\
\text { Deviation }\end{array}$} & \multirow{2}{*}{$\begin{array}{l}\text { Std. Error } \\
\text { Mean }\end{array}$} & \multicolumn{2}{|c|}{$\begin{array}{l}95 \% \text { Confidence Interval of the } \\
\text { Difference }\end{array}$} & \\
\hline & & & & & Lower & Upper & \\
\hline Pair 1 & $\mathrm{OC}-\mathrm{CS}$ & 1.02500 & 1.02501 & .16207 & .69719 & 1.35281 & 6.325 \\
\hline
\end{tabular}

As it is shown in table 4.1 the mean score of the OC group is $10.90(\mathrm{SD}=2.60)$ and that of the $\mathrm{CS}$ is $9.87(\mathrm{SD}=2.70)$ on the sepeech production ability, which shows OC's group suporiorety over the Cs group. The results of the this analysis revealed significant diffrences in language production between the children with pre-schoole aged sibilings at home and the children who don't.

Toddlers Scores On Comprehension Ability 
To investigate if there were a significant diffrence between the groups amount of comprehension ability the total score related to the comprehension part of the analysis was entered in to the SPSS. Table 2 shows the descriptive statestic related to the comprehnsion ability of the toddlers.

TABLE 2

DESCRIPTIVE STATISTICS: RESULTS OF PAIRED SAMPLE T-TEST RELATED TO COMPREHENSION ABILITY

\begin{tabular}{|c|c|c|c|c|c|c|c|c|}
\hline & \multicolumn{5}{|c|}{ Paired Differences } & \multirow[b]{3}{*}{$\mathrm{t}$} & \multirow[b]{3}{*}{ df } & \multirow[b]{3}{*}{ Sig. (2-tailed) } \\
\hline & \multirow[b]{2}{*}{ Mean } & \multirow{2}{*}{$\begin{array}{l}\text { Std. } \\
\text { Deviation }\end{array}$} & \multirow{2}{*}{$\begin{array}{l}\text { Std. Error } \\
\text { Mean }\end{array}$} & \multicolumn{2}{|c|}{$\begin{array}{l}95 \% \text { Confidence Interval of } \\
\text { the Difference }\end{array}$} & & & \\
\hline & & & & Lower & Upper & & & \\
\hline Pair $1 \quad$ OC - CS & -.52500 & .55412 & .08761 & -.70222 & -.34778 & -5.992 & 39 & .000 \\
\hline
\end{tabular}

The maximum score for this part of the analysis is 6 with the OC's group mean of 5.17(SD=0.98) and CS'sgroup mean score of $5.70(\mathrm{SD}=0.56)$. the results shows a significant diffrence on the mean score of the two groups related to their comprehension ability and surporisingly the suporiority of CS's group on comprehension ability.

\section{INTERPRETATION OF RESULTS AND DISCUSSION}

The current study examined the effect of preschool aged sibling on toddlers' language development. The main goal of this study was to investigate how different members of the family could affect different aspects of language development such as the ability to produce and comprehend the language. We found that an only child language production and comprehension differ from those of the children with a sibling around. Specifically the mean average score of an only child ability to produce sounds and words was higher than the mean average of the children with sibling(s). On the contrary the mean average score of the children with sibling(S) on their comprehension ability was higher.

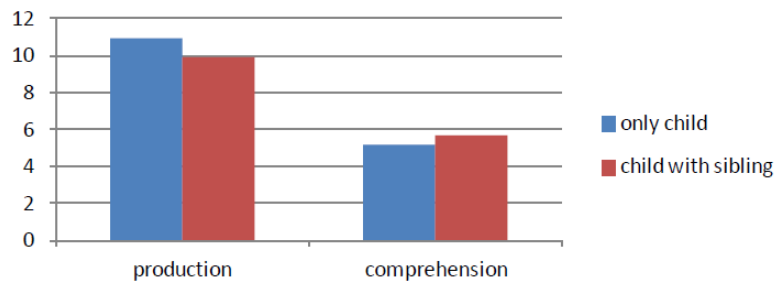

Graph 1: only child toddlers and the toddlers with preschool aged sibling language production and comprehension

Combined, these results support the conclusion that we are safe in accepting the first and second hypothesis that clear differences in language production and comprehension would be evident between the children with pre-schoole aged sibilings at home and the children who don't. the findings seem to add to the evidence prepared by Elizabeth Waters Wooden (2004).

The diffrences which are found in this research will actually fit well with the Bridge Hypothesis (Barton \& Tomasello 1994, Berko-Gleason 1975, Mannle \& Tomasello 1987). According to this view the learning environment which is provided by sibling and father is diffent from that which is provided by mother.Consequently children abitity to communicate linguistically will differ based on the presence of a sibling at home. According to the Bridge Hypotheses as sibling provide a more controversial circumestance for communicating, it is not ulikely that children interacting with them, especifically in play, would encounter a difrent and more complex linguistic environment than what they usually hear and communicate with their mothers. Eventually This context will broaden and empower their comprehension ability.

Another possible explanation for this diffrence could be the toddlers' expectation regarding diffrent family configuration. According to Strapp\&Federico(2000), We might expect that children's replies to siblings should differ from their replies to mothers because they hold different expectations of different family members. They know quit well that what the mother is searching for, while talkingto him, is awell formed utterance which could defintely make her happy, so they would try to say somthing as they know their mothers are waiting for a reply. This reaction was also evident in the interaction between the children and their mothers.

These findings are also cosistent with the earlier studies by Constance J. Wellen ( 1985) and Y. Oshima-Takane and M. Robbins (2003). In a study by Constance J. Wellen ( 1985), mothers were alone with their younger child, and in the other condition, an older sibling was also present. During the question-answer interactions, older siblings responded to $60 \%-65 \%$ of all mothers' questions before younger children had a chance to respond and provided direct answers to the questions in 57\%-65\% of those instances", the results from this study and the fact that the older sibling try to interpret the youger one intention and therfore reduce the chance of his production practice could be the other reason for hindering the child language production practice. The effect of older siblings' first responses also reduced by half the number of younger children's utterances. The younger children produced fewer noncontent and content answers and 
more imitated answers in the presence of the older sibling.", but at the same time, as the older sibling is a little more proficent in communicating linguistically,the toddlers language comprehension will improve due to a more complex and challenging language environment created by the sibling. This improvement in comprehension might even be due to the quality of the input which is provided by the mother at the present of the older sibling. In the same study by Constance J. Wellen (1985) she stated" Mothers responded by producing fewer rephrased questions, fewer questions providing hints and answers, fewer questions functioning as repetitions and expansions, and more directly repeated questions when the older sibling was present." This will reduce the amount of motherese talk which is a great source for language practice specificaly its production. It is concluded that the presence of older siblings may influence the language young children comprehend and produce.

\section{REFERENCES}

[1] Bates, E. (1979). the emergence of symbols: cognition and communication in infancy. New York: Academic Press.

[2] Barton, M. E. \& Tomasello, M. (1991). Joint attention and conversation in mother-infant sibling triads. Child Development 62, 517-29.

[3] Barton \& Tomasello. (1994). The rest of the family: the role of fathers and sibling in early language development. In C. Gallaway \& B. J. Richards (eds), Input and Interaction in Language Acquisition. Cambridge: Cambridge University Press, 10934.

[4] Berko-Gleason, J. (1975). Fathers and other strangers: their speech to young children. In D. Dato (ed.), Developmental Psycholinguistics: Theory and Application, Georgetown University Round Table on Languages and Linguistics; Washington: Georgetown University Press, 289-97.

[5] Bohannon, J. N. \& Stanowicz, L. (1988). The issue of negative evidence: adult responses to children's language errors. Developmental Psychology 24, 684-9.

[6] Chehalis M. Strapp and Amy Federico. (2000). Imitations and repetitions: what do children say following recast? First language journal 20,277-290

[7] Claire Elizabeth Andersen and Julie V. Marinac. (2007). Using an observational framework to investigate adult language input to young. Child Language Teaching and Therapy Journal.23,307-324

[8] Constance J. Wellen. (1985). Effects of Older Siblings on the Language Young Children Hear and Produce. Journal of Speech and Hearing Disorders. University of California, Santa Barbara.

[9] Debra C Vigil, Jennifer Hodges and Thomas Klee. (2005). Quantity and quality of parental language input to late-talking toddlers during play. Child Language Teaching and Therapy journal.21,107-122.

[10] Demetras, M. J., Post, K. N. \& Snow, C. E. (1986). Feedback to first language learners: the role of repetitions and clarification questions. Journal of Child Language, $12753-92$.

[11] Dunn, J. and Kendrick, C. (1982). The speech of two- and three-year-olds to infant siblings: 'baby talk' and the context of communication. Journal of Child Language 9, 579-96.

[12] Elizabeth Waters Wooden. (2004). The MacArthur-bates communicative development inventory as an assessment tool for lowincome, African American children published thesis Louisiana State University.

[13] Farrar, M. J. (1992). Negative evidence and grammatical morpheme acquisition. Developmental Psychology 28, 91-9.

[14] Hirsh-Pasek, K., Trciman, R. \& Schneiderman, M. (1984). Brown and Hanlon revisited: mothers' sensitivity to ungrammatical forms. Journal of Child Language, 11, 81-8.

[15] Jones, C. P. \& Adamson, L. P. (1987). Language use in mother-child-sibling interactions. Child Development 60, 356-66.

[16] Lieven, E. v. M. (1994) .cross linguistic and cross cultural aspects of language addressed to children. In C. Gallaway \&B. J Richards (eds), Input And Interaction In Language Acquisition. Cambridge: Cambridge University Press, 56- 73.

[17] McLaughlin, S. (1998). Introduction to language development. San Diego: Singular.

[18] Mannle, S., Barton, M. \& Tomasello, M. (1991). Two-year-olds' conversations with their mothers and preschool-aged siblings. First Language 12, 57-71.

[19] Mannle, S. \& Tomasello, M. (1987). Fathers, siblings and the bridge hypotheses. In K. E.Nelson and A. van Kleeck (eds), Children's Language Vol. VI. Hillsdale, NJ: Lawrence Erlbaum, 23-41.

[20] Nelson, K. E., Denninger, M. S., Bonvillian, J. D., Kaplan, B. J. \& Baker, N. D. (1984). Maternal input adjustments and nonadjustments as related to children's linguistic advances and to language acquisition theories. In A. D. Pellegrini \& T D. Yawkcy (eds), The Development of Oral and written languages: Readings in Developmental and Applied Linguistics (Norwood, NJ: Ablex), 31-56.

[21] shima-Takane, Y., Goodz, E. \& Derevensky, J. L. (1996). Birth order effects on early language development: do second born children learn from overheard speech? Child Development 67, 621-34.

[22] Penner, S. G. (1987). Parental responses to grammatical and ungrammatical child utterances. Child Development 58, 376-84.

[23] Post, K. N. (1995). Negative evidence in the language learning environment of lastborns in a rural Florida community. In K. E. Nelson \& Z. Reger (eds), Children's Language, Vol. 8. Hillsdale, NJ: Lawrence Erlbaum, 132-73.

[24] Rondal, J. A. (1981). On the nature of linguistic input to language-learning children. International Journal of Psycholinguistics $21,75-107$.

[25] Schaffer, H. R. \& Liddell, C. (1984). Adult-child interaction under dyadic and polyadic conditions. British Journal of Developmental Psychology 2, 33-42.

[26] Strapp, C. M. (1993). The development of syntax in toddlers: the role of older sibling' Linguistic input. Unpublished Master's thesis, University of Nevada, Reno.

[27] Strapp, C. M. (1999). Mothers', fathers', and siblings' responses to children's language errors: Comparing sources of negative evidence. Journal of Child Language, 26, 373-91. 
[28] Strapp, C. M., \& Federico, A. (2000). Imitations and repetitions: What do children say following recasts? First Language, 20 (3), 273-290.

[29] Tomasello, M., Farrar, J. \& Dines, J. (1983). Young children's speech revisions for a familiar and unfamiliar adult. Journal of Speech and Hearing Research, 27, 359-63.

[30] Tomasello, M. \& Mannle, S. (1985). Pragmatics of sibling speech to one-year-olds. Child Development 56, 911-17.

[31] Wellen, C. J. (1985). Effects of older sibling on the language young children hear and produce. Journal of Speech and Hearing Research, 50, 84-99.

[32] Wells, C. G. and Robinson, W. P. (1982). The role of adult speech in language In Fraser, C. and Scherer, K. R., editors, Advances in the social psychology of language. Cambridge: Cambridge University Press.

[33] Woollett, A. (1986). The influence of older siblings on the language environment of young children. British Journal of Developmental Psychology 4, 23 5-45.

[34] Y. Oshima-Takane and M. Robbins. (2003). Linguistic Environment of Second born Children. First language journal.

Elham Malmeer was born in Iran, has earned her MA in TESL at Teharn University (South Branch), and now is a PhD. Candidate majoring TESL at Islamic Azad University, Ahar Branch in Iran. She has been teaching English for about 7 years in different institutes and universities. Her main interest is testing and teaching English as a foreign language to Iranian learners. She is working on the Dynamic Assessment and its different applicability for Iranian language learners.

Nader Assadi, PhD in Applied Linguistics Research Vice-chancellor, Ahar Branch, Islamic Azad University. Authorized Translator to the Administration of Justice. 